\title{
E Research Square \\ Detection of child abuse on computed tomography
imaging due to presence of severe caries: A case report
}

hiroyuki tokue ( $\nabla$ tokue@s2.dion.ne.jp )

Gunma University Hospital: Gunma Daigaku Igakubu Fuzoku Byoin

\section{Azusa Tokue}

Gunma Daigaku Igakubu Fuzoku Byoin

\section{Yoshito Tsushima}

Gunma University Hospital: Gunma Daigaku Igakubu Fuzoku Byoin

\section{Case report}

Keywords: child abuse, computed tomography imaging, dental caries

Posted Date: November 17th, 2021

DOI: https://doi.org/10.21203/rs.3.rs-1059525/v1

License: (c) (i) This work is licensed under a Creative Commons Attribution 4.0 International License.

Read Full License

Version of Record: A version of this preprint was published at Oral Radiology on January 30th, 2022. See the published version at https://doi.org/10.1007/s11282-022-00591-5. 


\section{Abstract}

Background: Child abuse can result from physical, verbal, or sexual harm. While child abuse often involves an action that harms the child, inaction, such as neglect, can also cause harm.

Case presentation: We present a case in which child abuse was detected through computed tomography imaging findings of severe dental caries. This case was a 5-year-old girl who fell down the stairs and hit her head. The computed tomography of her head showed no abnormalities; however, severe dental caries was detected. The mother's incomplete history and inadequate explanation of injuries further made us suspect abuse. A whole-body computed tomography was conducted for child abuse screening, which showed an unnatural fracture in the left arm. Through these imaging findings, we were able to identify and help a victim of child abuse.

Conclusions: Physicians should be aware that severe dental caries may be a sign of child abuse.

\section{Background}

Child abuse can result from physical, verbal, or sexual harm. While child abuse often involves an action that harms the child, inaction, such as neglect, can also cause harm [1].

Here, we present a case of child abuse detected on computed tomography (CT) through the identification of severe caries. Dental neglect could be an important indicator of abuse on the child abuse/neglect spectrum.

\section{Case Presentation}

After falling down the stairs and hitting her head, a 5-year-old girl came to the hospital with her mother. The patient's height and weight were age-appropriate. No paralysis was observed in the limbs. Although she was conscious, the patient underwent a head CT at the time of admission because of a persistent headache. The CT of her head showed no abnormalities. However, although the attending physician was ready to discharge the patient without any special treatment, the radiologist noticed that the caries detected on CT was quite severe (Figure 1a, 1b). The radiologist, therefore, suspected child abuse and informed the attending physician, who conducted a detailed interview with the mother. The mother stated that the patient was always licking candy and refused to brush her teeth. She also stated that the girl's teeth might have been genetically weak. However, there were many inconsistencies in her story. After a detailed examination, the attending physician found multiple bruises on her body. A whole-body CT scan was performed to screen for evidence of child abuse, and an unnatural fracture was identified in the left arm (Figure 1c). The incomplete history and inadequate explanation of injuries convinced us that the patient was a victim of child abuse. After alerting the mother of these findings, we referred the mother to social services. With the mother's consent, the girl then began to live in a child welfare institution.

\section{Discussion And Conclusions}


The American Academy of Pediatric Dentistry defines dental neglect as the willful failure of parents or guardians, despite adequate access to care, to seek and follow through with the treatment necessary to ensure a level of oral health essential for adequate function and freedom from pain and infection [2]. Although past reports vary, between $23 \%$ and $58 \%$ of children with severe caries are being abused [3-5]. There appears to be a strong association between severe dental caries and child abuse and neglect [6]. Therefore, severe dental caries could be an early symptom of child abuse and neglect.

Child abuse is a grave violation of a child's fundamental rights and is a significant international public health concern. Efforts to combat child abuse are necessary worldwide. It is a violation of a child's human rights to be abused by a caregiver who is, in principle, the source of safety and security. In the worst cases, child abuse can lead to death. It is essential, therefore, that healthcare professionals are aware of any signs of child abuse. CTs should be the primary tool for screening for child abuse involving head trauma. However, if we focus only on the brain and skull on CT imaging, dental abnormalities will likely be overlooked.

The true prevalence of child abuse involving severe caries is difficult to determine, as many cases have never been reported/investigated or are simply not recognized [6]. Dental neglect can be an indicator of general child neglect. However, diagnosing dental neglect is challenging. Therefore, a radiologist who can make objective decisions may have an advantage in identifying child abuse.

To the best of our knowledge, no previous report has presented a case of child abuse detection through the identification of severe dental caries on head CT. Due to radiation exposure, performing CTs on children is generally avoided. However, if severe dental caries is identified, we should consider the possibility of abuse and perform a full-body examination [7].

In conclusion, child abuse is an odious act that deserves absolute condemnation. We can sometimes find evidence by chance, and in these cases, we must take a proactive role in helping the victims. Healthcare providers (including radiologists specializing in interpretation) should be aware of the association between serious dental caries and child abuse.

\section{Abbreviations}

CT: computed tomography

\section{Declarations}

\section{Ethics approval and consent to participate}

Written informed consent was obtained from the patient's legal guardians for publication of this case report and any accompanying images. A case report is not required institutional review board (IRB) in our institution. 
Acknowledgements

Not applicable.

\section{Competing Interests}

The author(s) declared no potential conflicts of interest.

\section{Funding}

The author(s) received no financial support.

\section{Author's contributions}

$\mathrm{HT}$ : Design of the work, acquisition of Data, wrote the manuscript, corresponding author. AT, YT: Design of the work, wrote the manuscript, revision of the manuscript. All authors participated in the design of the case report and wrote the manuscript and designed the format of figures. All authors read and approved the final manuscript.

\section{Consent for publication}

Written informed consent was obtained from the patient's legal guardians for publication of this case report and any accompanying images. A case report is not required institutional review board (IRB) in our institution.

\section{Availability of data and materials}

All data generated or analyzed during this study are included in this manuscript.

\section{References}

1. I Fayaz. Child Abuse: Effects and Preventive Measures. International Journal of Indian Psychology. 2019; 7(2), 871-884.

2. American Academy of Pediatrics Committee on Child Abuse and Neglect, American Academy of Pediatric Dentistry, American Academy of Pediatric Dentistry Council on Clinical Affairs. Guideline on oral and dental aspects of child abuse and neglect. Pediatr Dent. 2008;30(7):86-89.

3. Valencia-Rojas N, Lawrence HP, Goodman D. Prevalence of early childhood caries in a population of children with history of maltreatment. J Public Health Dent. 2008;68(2):94-101.

4. Sillevis Smitt H, de Leeuw J, de Vries T. Association Between Severe Dental Caries and Child Abuse and Neglect. J Oral Maxillofac Surg. 2017;75(11):2304-2306.

5. Valencia-Rojas N, Lawrence HP, Goodman D. Prevalence of early childhood caries in a population of children with history of maltreatment. J Public Health Dent. 2008;68(2):94-101. 
6. Bhatia SK, Maguire SA, Chadwick BL, Hunter ML, Harris JC, Tempest V, Mann MK, Kemp AM. Characteristics of child dental neglect: a systematic review. J Dent. 2014;42(3):229-239.

7. Brenner DJ, Elliston C, Hall E, et al: Estimated risks of radiation induced fatal cancer from pediatric CT. Am J Roentgenol. 2001;176:289-296.

\section{Figures}
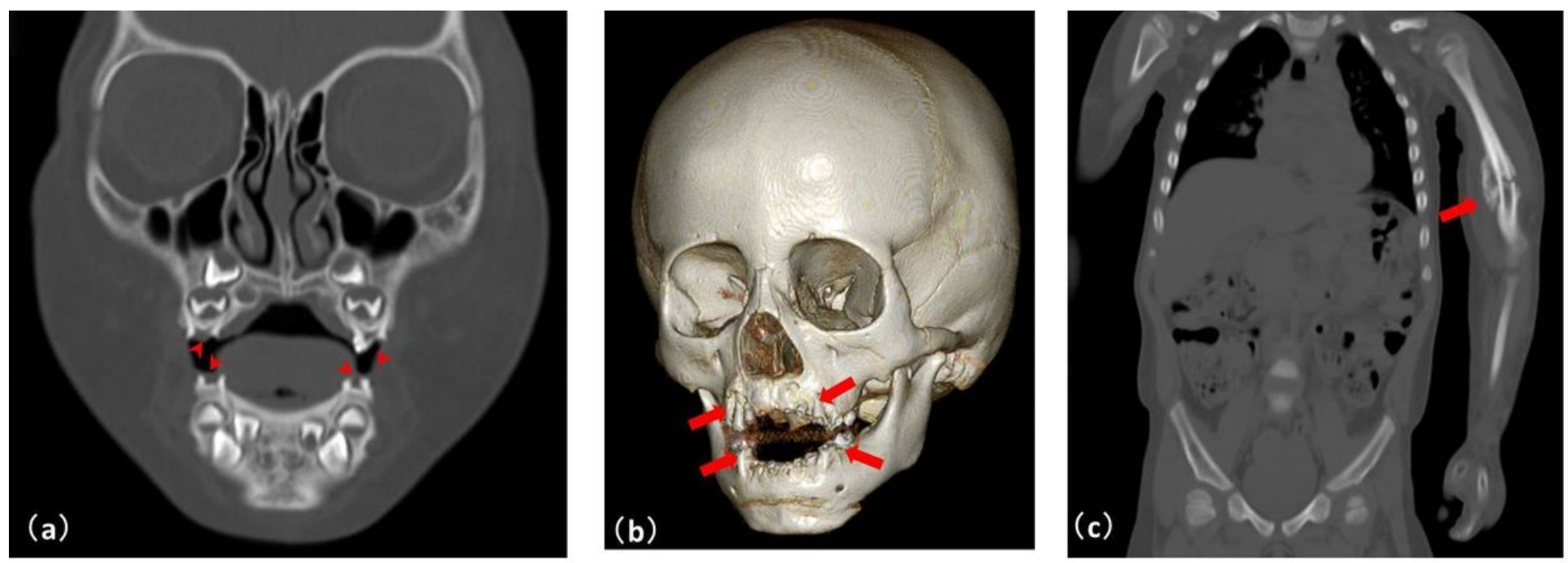

\section{Figure 1}

A 5-year-old girl fell down the stairs and injured her head. She underwent a head CT because she had a persistent headache. The CT of her head (a) shows no abnormalities; however, multiple untreated cavitated dentin carious lesions are present (arrowheads). An additional 3-dimensional CT (b) shows many rotten teeth (arrows), and a whole-body CT for child abuse screening (c) shows an unnatural fracture in the left arm (arrow).

\section{Supplementary Files}

This is a list of supplementary files associated with this preprint. Click to download.

- CAREchecklistEnglish20131.pdf 